\title{
Fostering Media Literacy Skills in the EFL Virtual Classroom: A Case Study in the COVID-19 Lockdown Period
}

\author{
Marina Bilotserkovets, Tatiana Fomenko, Oksana Gubina, \\ Tetiana Klochkova and Oksana Lytvynko \\ Sumy National Agrarian University, Sumy, Ukraine \\ https:// orcid.org/0000-0003-4692-3444 \\ https://orcid.org/0000-0002-3048-7097 \\ https://orcid.org/0000-0002-3575-5898 \\ https://orcid.org/0000-0002-1173-6211 \\ https://orcid.org/0000-0002-2241-3776 \\ Maryna Boichenko \\ Sumy State Pedagogical University, Sumy, Ukraine \\ https://orcid.org/0000-0002-0543-8832 \\ Olena Lazareva \\ Kharkiv National Pedagogical University, Kharkiv, Ukraine \\ https://orcid.org/0000-0003-4385-0139
}

\begin{abstract}
This investigation highlights the ways and means of students' formation of media literacy skills under the conditions of total and emergent distance learning in the lockdown period of the COVID-19 pandemic. The case study involved 138 first-year students from Sumy National Agrarian University, Ukraine, who studied English as a foreign language (EFL). Analysis, synthesis, and generalization of scientific data were conducted to determine the requirements and materials for the survey. Media literacy of the participants in the experimental group was developed through performance of a series of social media projects, critical analysis of social media texts, and creation of social media content. Pedagogical observation and expert estimation were employed to obtain qualitative results of partiucipants' progress during practical classes and extracurricular activities. Psychological techniques and mathematical methods were employed to measure and assess the quantitative data of the experiment. The outcomes of the study revealed the positive dynamics of the development of reflective-evaluative, collaborative, and searching-creative skills of participants in the experimental group as well as improvement in their English proficiency. The result of this study is potentially appropriate for educators who are
\end{abstract}


interested in the application of media technologies in foreign-language teaching.

Keywords: distance learning; media literacy skills; pandemic period; social media; teaching EFL

\section{Introduction}

An emergent shift of the majority of educational institutions worldwide to distance learning in the virtual academic environment occurred due to the spread of the COVID-19 pandemic. Most students had to study remotely from their homes through the internet (Assalahi, 2020; Goh \& Sandars, 2020). In the period of total lockdown, students and academics had to use media, especially social media, for supporting the learning process, which was facilitated through various digital means (Zoom, Google Meet etc.) and educational platforms (Moodle, Google Classroom etc.). They applied and presented the results of their scientific works through social media groups (Facebook, Instagram, Twitter etc.); online libraries and torrent sites were often the only sources of knowledge and information for learners (Marinoni et al., 2020; Ogbonnaya et al., 2020).

In terms of learning English as a foreign language (EFL), media sources are of utter importance as they provide students with a variety of information about linguistic discourses, language structures, pronunciation, and grammatical patterns. In addition, they serve as a guidance in social interactions and cultural values in particular language communities. However, the spread of digital content following COVID-19 exposed students to a vast amount of information through media, often false or inaccurate (Marinoni et al., 2020). More than ever before, students are in crucial need of the media literacy skills that would allow them to identify the nature of information they are surrounded by; find out if it is useful and credible; and protect themselves from misinformation and take control over what they read, listen to, or watch in the media.

The aim of the paper was to explore how students' media literacy skills were developed for efficient application of social media resources in the EFL virtual classroom in the lockdown period of the COVID-19 pandemic. The objecives of the paper included revising recent scientific research to prepare the materials and requirements for the case study; implementing social media activities in the process of EFL training of the experimental group of student participants; and determining whether social media technologies have the potential to improve the EFL proficiency of students.

\section{Literature review}

Nowadays, media in education have a stable position. Ytreberg (2002) investigated the role of media technologies in constructing an educational environment involving interactive learning and student-created content. The author pointed out that media in education suggest both cognitive and affective practices. Media provoke discussion, self-esteem, and assessment of values because media content mostly has a strong emotional impact (Ytreberg, 2002). Furthermore, studies have shown that people learn abstract ideas and new 
concepts more easily when they are presented in both verbal and visual form (Schmidt, 2012). Another essential function of media, and in particular social media, is the significant transformation of teacher-student interactions and innovative support of cooperation between students and academia (Chen \& Bryer, 2012).

When social media sources are employed in foreign-language learning, students become co-authors of learning information content and partners and co-producers of the educational process. They thereby contribute to the establishment of a new kind of student-centered approach, "an approach that puts the student's ability to communicate and produce content in the focus of the educational activities" (Pfeffer, 2014, p. 93). Moreover, as a means of communication, social media include teaching technologies that can greatly contribute to the creation of an authentic linguistic environment for foreign-language learners (He, 2019). Forming communicative competence through social media, students are presented with a scenario where they can produce their information content from media models, applying and imitating the foreign-language patterns and intonations that tend to be most similar to real communicative practices and situations (Mc Dermott, 2013).

However, if educators and students want to wholly benefit from media implemented in their learning process, they need to embrace their analytical and critical abilities to become media literate. Modern scholars have defined media literacy as a combination of knowledge and skills necessary for people to orient themselves in an information-based environment, search and share information, interact with other people and computer software, create safe and reliable media content, filter the media content, and solve cognitive tasks (Andriushchenko et al., 2020; Hatlevik et al., 2015). Analysis of recent scientific sources has shown that media literacy deals with the leveling of artificially created information structures and understanding of the principles of their creation. In addition, it deals with the ability of people to interpret the meaning of media messages based on personal experience and such individual characteristics as personal requests and expectations, formed national and gender ideas, social and cultural backgrounds etc. Media literate citizens are aware of different opinions and form their own position on current issues (Dvorghets \& Shaturnaya, 2015; Pfeffer, 2014).

Being cross-disciplinary by nature (Schmidt, 2012), media literacy has been investigated from different points of view, but pedagogic research exploring the integration of media literacy and learning foreign languages is scant. A critical media literacy approach included in the foreign-language curriculum has been vectored by academia worldwide to develop learners' critical reading of media content, thereby enabling their perception of media messages as a distorted version of reality. Moreover, this approach has encouraged and motivated students' progress in foreign-language learning by involving their culture and interests amidst the learning process. Instructors intend to assist learners in their discovery of ties between language and social, cultural, and political spheres of its application, as well as materials and topics that have analogies in their native- 
language culture by exploring own identities and divarication in comparison to other peoples (Reagan \& Osborn, 2002).

A critical intercultural approach to teaching EFL has been implemented to develop the intercultural communication skills of students, and their critical thinking, social, and reflexive skills (Gómez Jiménez \& Gutiérrez, 2019). The National Council of Teachers of English (NCTE) formulated the core components for media literacy necessary in the process of teaching EFL. These are the abilities to navigate, process, and synthesize multiple sources of information; compile, analyze, and critically evaluate multimedia texts; create and spread messages for virtual communities worldwide; start fruitful and respectful cross-cultural relationships with others by adopting the ethical responsibilities crucial for complex environments; and improve proficiency and skillfulness with digital technologies (ACTFL, n.d.).

Exploring the scientific works on media literacy implementation, we intended to identify the skills necessary to compose students' professionally oriented communicative competence in EFL. An overview of the latest studies (Baglari et al., 2020; Bal \& Bicen, 2017) revealed the following three types of skills that are crucial for teaching EFL using a media literacy approach:

- skills to search and choose important information out of multiple diversified internet sources and assess its status, reliability, and acceptance;

- skills to construct and present professionally oriented content in various media formats and genres, taking into consideration the target audience and algorithms of how media influence the application of tools; and

- skills to collaborate and benefit from the participation in different digitally mediated research organizations, social networks, and virtual project groups for gaining professional knowledge and intercultural experience.

\section{Methodology}

\subsection{The goal of the investigation}

This case study was conducted to answer the following questions:

1) What are the most commonly used social media amongst students and what are they utilized for?

2) What do educators need to do to develop students' critical media literacy skills through learning English?

3) In what way does the critical media literacy approach affect the improvement of students' proficiency in EFL?

\subsection{Participants}

A sample of 138 students was determined for the survey. The participants voluntarily participated in this study. The experimental group included 70 first-year students, and the control group consisted of 68 first-year students. The experimental and control groups were selected in such a way that the controlled parameters did not differ significantly. The data concerning the features of the participants of the study are presented in Table 1. 
Table 1: Participant features

\begin{tabular}{|l|l|l|l|}
\hline $\mathbf{N}$ & Feature & Experimental group & Control group \\
\hline 1. & Age & $17-19$ years old & $17-19$ years old \\
\hline 2. & Gender & $\begin{array}{l}46 \% \text { female } \\
54 \% \text { male }\end{array}$ & $\begin{array}{l}45 \% \text { female } \\
55 \% \text { male }\end{array}$ \\
\hline 3. & $\begin{array}{l}\text { English language } \\
\text { knowledge level }\end{array}$ & $\begin{array}{l}\text { B1 (according to the } \\
\text { international certification } \\
\text { levels) }\end{array}$ & $\begin{array}{l}\text { B1 (according to the } \\
\text { international certification } \\
\text { levels) }\end{array}$ \\
\hline 4. & $\begin{array}{l}\text { Number of English } \\
\text { classes per week }\end{array}$ & 2 & 2 \\
\hline 5. & Future specialties & $\begin{array}{l}\text { Agronomy, Food } \\
\text { Technologies, Livestock } \\
\text { Technologies, } \\
\text { Management, Geodesy }\end{array}$ & $\begin{array}{l}\text { Agronomy, Food } \\
\text { Technologies, Livestock } \\
\text { Technologies, Management, } \\
\text { Geodesy }\end{array}$ \\
\hline
\end{tabular}

\subsection{Limitations}

The major methodological limitation of the research was that the outcome depended highly on the context and case, along with the application of mostly exploratory and descriptive methods. The study was carried out at Sumy National Agrarian University (SNAU), Ukraine. Its findings are thus limited to the sample of participants and the institution where the research took place.

The research was conducted from March to July 2020. The time interval for this survey was limited to the mentioned term because that period involved exclusive and emergent distance learning, where students and academics worked under the conditions of the total lockdown, caused by the COVID-19 pandemic. During this period, EFL classes were delivered utilizing digital and social media facilities such as Zoom, Moodle, Google Classroom, Facebook, and Instagram.

The obtained data were verified by cross-checking and member-checking. The reliability factor for the questionnaire and diagnostic techniques used in the survey produced values from 0.85 to 0.91 (at $\mathrm{p}<0.01$ ), indicating the high reliability of the questionnaire items. The sample, consisting of 138 participants, determined the margin of error (at the $90 \%$ confidence level) for this research at about $7 \%$.

The authors did not attempt to quantitate data on the linguistic knowledge and skills improvement, regarding it as a prospect of future study.

\subsection{Methods and pedagogical conditions}

A set of theoretical methods was used to prepare the requirements and materials for the survey. This included analysis, synthesis, explanation, and generalization of the scientific data. Pedagogical observation of the participants and the expert estimation method were employed to obtain qualitative results. The survey was administered by lecturers and tutors who were watching over the participants' progress during practical classes and extracurricular activities. Psychological techniques and mathematical methods were applied to measure and assess the results of the study. 
The research work on implementing media literacy tools into the course of learning EFL in SNAU was implemented according to the following pedagogical conditions:

1) creating a relaxed atmosphere, mutual trust, and psychological comfort in teacher-student and student-student interactions;

2) appropriately using the polysemous nature of information and the principle of improvization;

3) encouraging different interpretations of information, recognizing the equality of viewpoints of all participants concerning the information; and

4) focusing on close ties with the socio-cultural environment, interests, and life experience of the participants.

\subsection{Organization of the experimental work}

To answer the research questions, experimental work was conducted. The participants involved in the study were divided into an experimental and a control group. During the experiment, participants of both groups conducted distance learning through online learning platforms. The control group used their usual textbooks, grammar books etc. instead of social media materials, thus using no media literacy tools during their EFL classes.

Teaching EFL to the experimental group was based on authentic social media materials. Participants were asked to identify its multifunctional nature and specifics of its presentation to different public groups; and to research the role of social media networks in the academic environment and professional socialization, and what its educational potential is.

At the beginning of each lesson, a specific survey was adminstered which aimed at identifying the range of student tastes, personalized features of the academic groups, and student expectations from the lesson. Several tests were also conducted to explore if the participants were ready to work with the media; how well they knew the modern world of media (social and mobile networks, mass media, popular sites, TV and radio programs, specialized publications etc.); if they possessed the skills to assess media events; whether they were able to defend own opinions; their propensity to fall under the influence of 'authorities' etc. (see Appendix 1). Media literacy tools were implemented with different creative tasks that contributed to the acquisition of knowledge about the methods of perception and analysis of social media texts, the application of this knowledge in various professionally oriented situations, and the development of experience in creating competent and correct social media texts.

In the course of the experimental work, social media posts, TV and radio programs, and materials of various internet sites, on the same topic but from different sources, were discussed and compared in attempts to detect their specific features. Such discussions were built on the principle of antithesis and paradox, organized as a dialogue, conversation, or dispute, which allowed the identification of different points of view that existed amongst the participants on the same issue. The participants' critical analysis abilities were elicited by 
employing the following key questions, formulated for the study on the basis of recommendations by Mendoza (2018) and other experts in digital and media literacy:

1) Who is the author of the article (post) under review? This point enabled participants' realization that all media content is created by a diversity of authors, each of them having a unique discourse, agenda, vision, and background.

2) What technologies are applied to draw the attention of the audience? This questions helped participants to systematize their knowledge on various tools and means used by digital media to keep the audience interested in videos, commercials, or apps.

3) What multiple interpretations of one particular message are possible? Here, the participants could reflect on the point that different communities can perceive a specific message in different ways.

4) Whose discourses, traditions, lifestyles, positions, and values are expressed or absent? Sometimes, not all perspectives and voices are represented, especially from certain strata of the society. It was essential to find out what views were missing and why.

5) What reason is this message sent for? This point was brought up so participating students could try to understand the author motives in the creation and sharing of messages and how they benefited from them.

Social media facilities, such as online platforms, forums, and chats, were used as educational tools in various learning activities and projects of the participants. Participants were required to set out the solution of the problem, express their own opinion, or argue their position on a specific aspect of the problem. The participants discussed multifaceted aspects of professional activities in the information society and developed the insights necessary to critically assess the messages embodied in the social media content. In addition, they practiced the application of strategies for analyzing, reflecting, critiquing, and interpreting social media content that consisted of both visual and textual elements (in particular professionally oriented social networks).

Some participants did not feel confident enough to report in English in front of others. Therefore, the participant groups were divided into smaller subgroups, with their chat rooms, where they discussed matters related to the project. The activities of the subgroups were organized into two parts. First, each subgroup worked on gathering information on a particular topic, whereafter the subgroup members reported their findings to the whole subgroup. Second, the collective preparation of a creative task as a result of mastering certain learning material took place. Consequently, all subgroups presented their projects to the whole group, and the participants from the other subgroups wrote comments and questions based on this. It thus turned into a written dialogue, where participants who were otherwise not so talkative became engaged and took part in the discussion. The participants created multimedia presentations to show them for disputation regarding the coursework and posted them on social networks. Projects on the following topics were presented: "Academic environment socializing: Online versus offline", "Security and balance in social 
network maintenance", "Fake news: Who cares and who profits?", "Gender stereotypes presented in media" etc.

During the period of the study, three online trainings were held on the following topics: "Professional communities in a social media environment", "Successful fundraising and projects development by means of social media platforms", and "Media literacy skills of a student as a condition of his/her successful personal and professional self-realization".

The following were achieved during the trainings with the participants as an interactive form of education:

1) becoming aware of interaction through social media in the professional sphere;

2) mastering skills to critically analyze information and messages received from media;

3) developing self-awareness and self-determination of their social positions; and

4) forming skills to critically evaluate information reproduced by social media.

\section{Results}

It was found that most participants had more than one social media account. The outcomes of this aspect are presented in Figure 1.

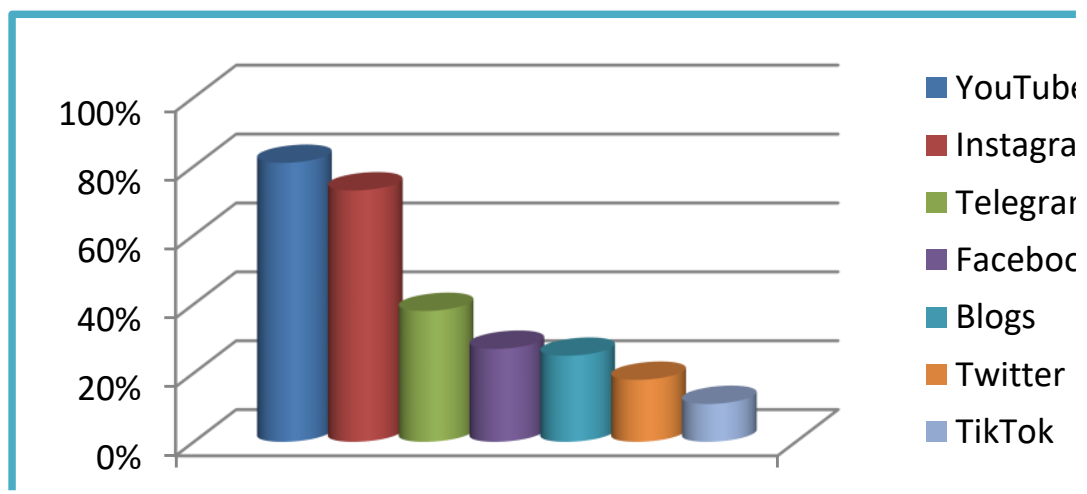

Figure 1. The most commonly used social media networks amongst participants

The most commonly used social media networks amongst the participants were YouTube (81\%), Instagram (73\%), Telegram (38\%), and Facebook (27\%). Fewer participants reported that they filmed video blogs or read or wrote blogs $(25 \%)$, or used Twitter $(18 \%)$ or TikTok $(11 \%)$. These social media networks were used by the participants for educational purposes (to share organizational information, learning materials, and assignments or to discuss university-related issues in chats or comments); as well as for socialization, small talk, and entertainment, such as posting humorous photographs or video clips.

Since media literacy is perceived as a dynamic phenomenon that reflects the ability of individuals to effectively use the potential of the media environments for personal and professional purposes, consciously perceive and critically 
evaluate information from media sources, as well as effectively apply media technology, three components of student media literacy were identified. These are reflective-evaluative, collaborative, and searching-creative media literacies. The assessment of indicators was recorded at three basic levels - high, medium, and initial, which was fully consistent with the tradition of the pedagogical research. The corresponding results are given in Table 2 .

Table 2: The dynamics of participants' critical media literacy formation

\begin{tabular}{|c|c|c|c|c|c|c|c|c|}
\hline \multirow{2}{*}{\multicolumn{3}{|c|}{$\begin{array}{l}\text { Level } \\
\text { Group }\end{array}$}} & \multicolumn{2}{|c|}{ High } & \multicolumn{2}{|c|}{ Medium } & \multicolumn{2}{|c|}{ Initial } \\
\hline & & & EG & CG & EG & CG & EG & CG \\
\hline \multirow{6}{*}{ 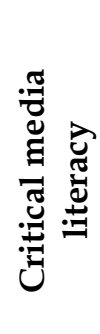 } & \multirow{2}{*}{$\begin{array}{l}\text { Reflective- } \\
\text { evaluative }\end{array}$} & Before study & 18.1 & 17.3 & 30.2 & 34.0 & 51.6 & 48.6 \\
\hline & & After study & 30.7 & 19.3 & 48.4 & 43.1 & 20.8 & 37.5 \\
\hline & \multirow[t]{2}{*}{ Collaborative } & Before study & 22.6 & 18.7 & 39.1 & 37.9 & 38.2 & 43.3 \\
\hline & & After study & 37.2 & 18.4 & 56.1 & 38.9 & 6.6 & 42.6 \\
\hline & \multirow{2}{*}{$\begin{array}{l}\text { Searching- } \\
\text { creative }\end{array}$} & Before study & 18.7 & 11.4 & 42.8 & 42.1 & 38.4 & 46.4 \\
\hline & & After study & 36.3 & 12.3 & 53.1 & 43.0 & 10.5 & 44.6 \\
\hline
\end{tabular}

The dynamics of the formation of participants' reflective-evaluative media literacy component was measured by means of an instrument by Karpov and Ponomareva (2000), adapted for this study. It expressed the degree of formation of emotional states and attitudes. The instrument assigned points as follows: a) proficiently formed reflective-evaluative skills - 3 points; b) satisfactorily formed reflective-evaluative skills - 2 points; c) superficially formed reflectiveevaluative skills -1 point; and d) a lack of reflective-evaluative skills -0 points. The changes in the levels of reflective-evaluative skills are presented in Figures $2 \mathrm{a}$ and $2 \mathrm{~b}$.

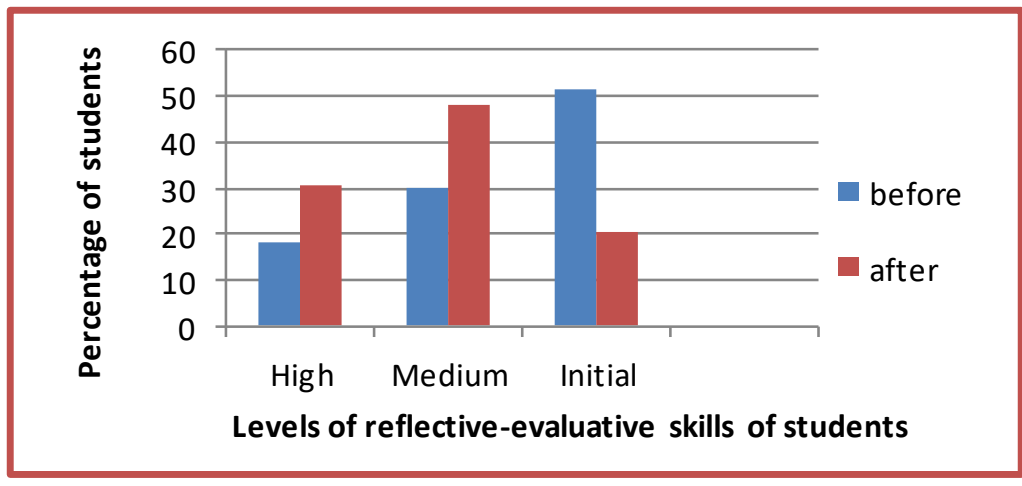

a) Experimental group 


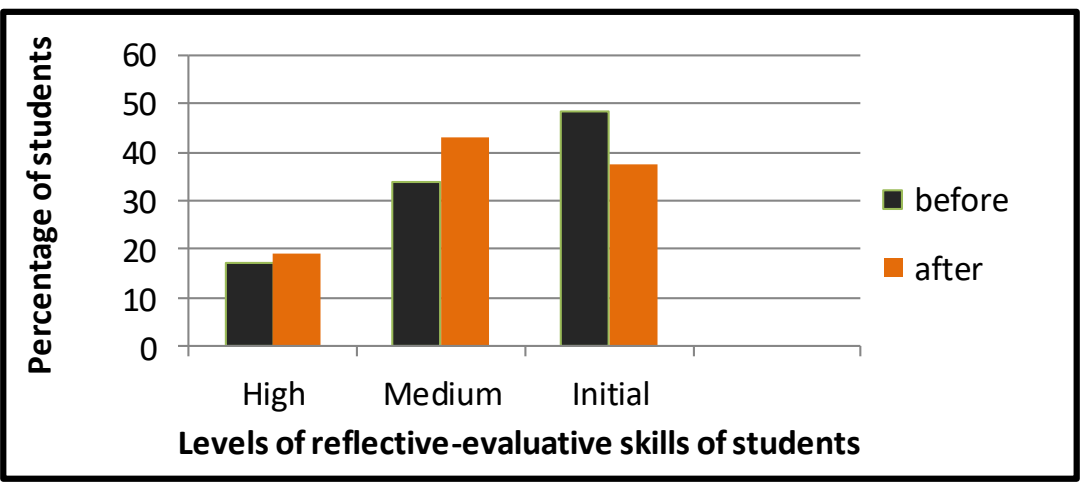

b) Control group

Figure 2. Changes in the levels of reflective-evaluative skills of participants for the a) experimental group and $b$ ) control group

The collaborative component, which measured the participants' skills to collaborate and benefit from the participation in different digitally mediated entities, was determined using the authors' instrument for the self-assessment of collaborative skills (see Appendix 2). The instrument assigned points as follows: a) proficiently formed collaborative skills - 3 points; b) satisfactorily formed collaborative skills - 2 points; c) superficially formed collaborative skills 1 point; and d) a lack of collaborative skills - 0 points. The changes in the levels of collaborative skills are presented in Figures $3 \mathrm{a}$ and $3 \mathrm{~b}$.

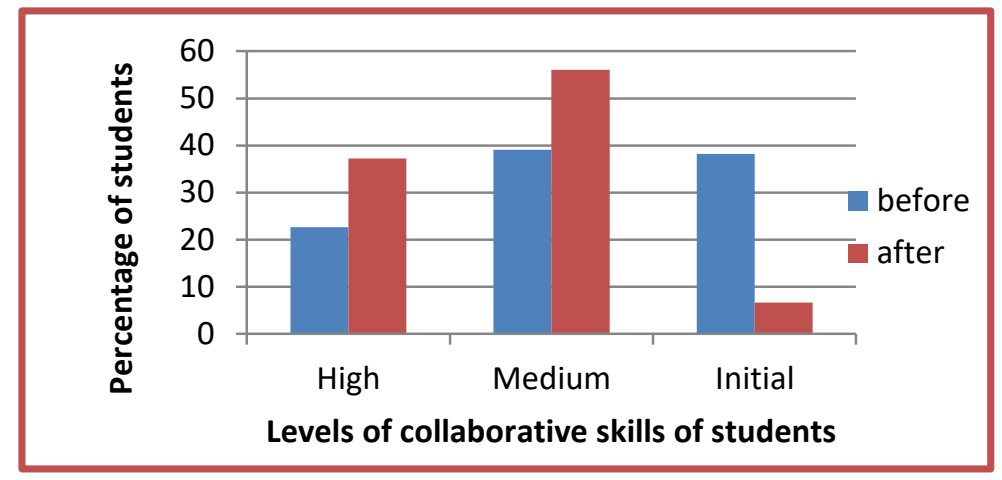

a) Experimental group

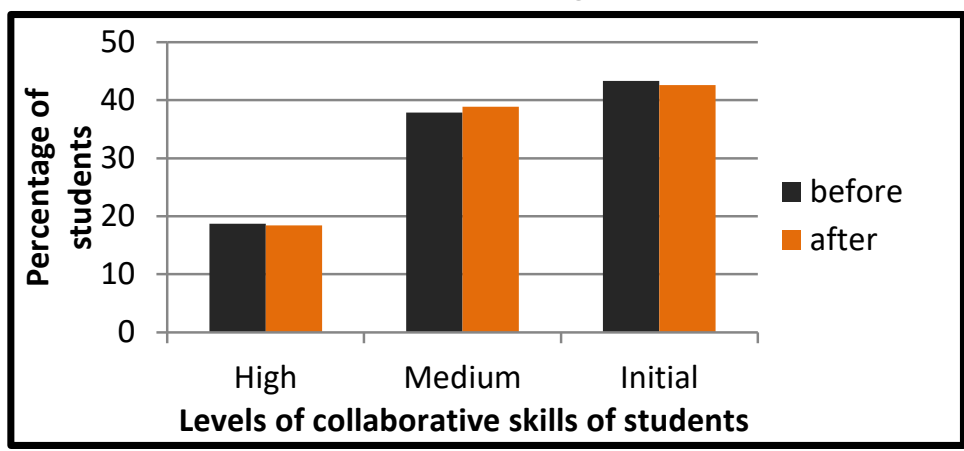

b) Control group

Figure 3. Changes in the levels of collaborative skills of participants for the a) experimental group and $b$ ) control group 
The searching-creative component, which expresses a set of explorative searching-creative skills, was determined through a modified instrument of 'Media research in professional activity' (Kuzmina, 2011). The instrument assigned points as follows: a) proficiently formed searching-creative skills 3 points; b) satisfactorily formed searching-creative skills - 2 points; c) superficially formed searching-creative skills - 1 point; and d) a lack of searching-creative skills - 0 points. The changes in the levels of searchingcreative skills are presented in Figures $4 \mathrm{a}$ and $4 \mathrm{~b}$.

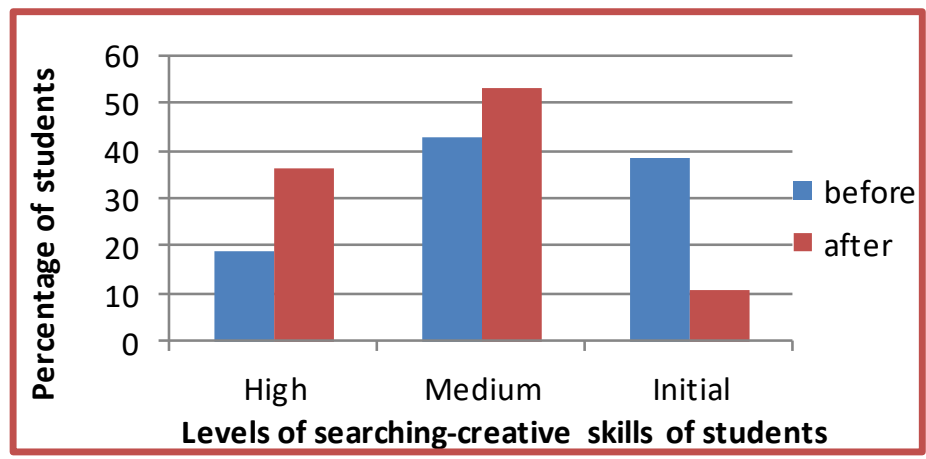

a) Experimental group

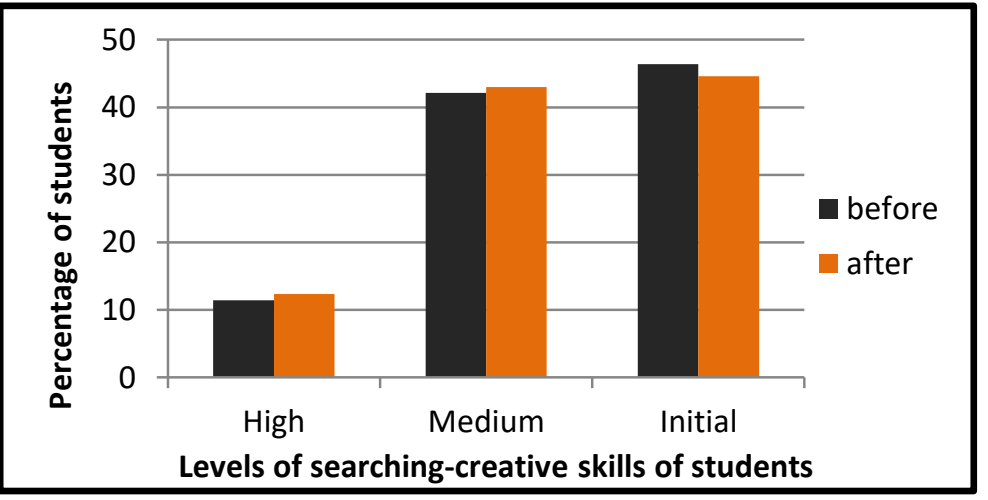

b) Control group

Figure 4. Changes in the levels of searching-creative skills of participants for the a) experimental group and b) control group

According to Table 2 and Figures $2 a, 2 b, 3 a, 3 b, 4 a$, and $4 b$, we could trace the positive dynamics of media literacy formation amidst the participants from the experimental group, who were taught EFL based on social media materials through the implementation of social media tools. As for the participants of the control group, these indicators remained almost unchanged. Thus, the generalization of the research outcomes proved the effectiveness of the implementation of social media tools and means into the process of learning EFL by the participants.

The next stage of the study was carried out to investigate in what way mastering media literacy tools and means affected participants' proficiency in EFL. The participants were administered a questionnaire to determine the prior factors that had contributed to the improvement in their EFL proficiency in the process 
of practicing social media activities (see Appendix 3). The data from the processed questionnaires are presented in Table 3.

Table 3: The priority of factors that influenced the participants' improvement in English proficiency by means of social media implementation

\begin{tabular}{|c|l|c|}
\hline $\mathbf{N}$ & $\begin{array}{l}\text { Factors that influenced participants' improvement in } \\
\text { English proficiency }\end{array}$ & $\begin{array}{l}\text { Priority for the } \\
\text { participants (\%) }\end{array}$ \\
\hline 1. & Increasing motivation & $92 \%$ \\
\hline 2. & Communication skills practice & $82 \%$ \\
\hline 3. & Authentic learning materials from social media & $76 \%$ \\
\hline 4. & ICT application in the process of learning & $73 \%$ \\
\hline 5. & Interactive teaching techniques & $58 \%$ \\
\hline
\end{tabular}

Most participants (92\%) identified increased motivation for studying EFL as major factor influencing their improvement in English proficiency. They highly appreciated social media projects and searching activities, singling out the abundance of information on the English language sites necessary to prepare them for fully fledged professional activities. They also highlighted the importance of being able to critically analyze the available media resources and being capable of joining and collaborating with international professional virtual communities through social media. Communication skills practice was also identified as a prime concern by many participants (82\%), who were positively disposed toward participation in Moodle and other social media forums. By communicating through social media, they could learn from each other by posting comments on other students' forums and presenting blogs to their groupmates. Seventy-six percent $(76 \%)$ of participants admitted that social media offered them the opportunity to learn different speech patterns and discourse information directly from native speakers. Almost the same number of participants $(73 \%)$ stressed the possibility to learn EFL with the help of ICT, various gadgets, and software. Teaching by means of social media is interactive by nature, with a considerable number of participants $(58 \%)$ regarding this factor as crucial for their EFL-knowledge and -skills improvement.

In conclusion, the improvement of participants' EFL proficiency was greatly affected by the development of their reflective-evaluative, collaborative, and searching-creative skills. These skills served to motivate and enable them to utilize social media potential for achieving professional and personal progress.

\section{Discussion}

The global academic community faced many challenge brought on by the COVID-19 pandemic. On the one hand, it was a test of students' preparedness to learn independently through the internet, to cope with learning tasks and problems within virtual communities. On the other hand, it tested teachers and educational institutions' awareness of and readiness for exclusive and emergent distance education and their ability to foster student skills essential for training and functioning in the virtual media environment. 
Being representatives of Generation Z or centennials (Bubich et al., 2016), modern students are bound to information accessibility, capable of quickly processing considerable amounts of information and multi-tasking. They spend ample time on media and social networks for pleasure and learning (Brocca, 2020). The latest research investigating the academic process in the period of the COVID-19 pandemic has shown that students can often act as passive receivers of knowledge, preferring to accept and internalize any presented information (Assalahi, 2020). In one study, students were interviewed during the course of the study, claiming that they underwent learning without the permanent guidance of lecturers, thus searching for information and doing assignments on their own. Moreover, they regarded their studies ineffective without discussing learning material with a teacher and groupmates (Rahiem, 2020).

To deal with the pandemic problems, educators encouraged learners to take advantage of a wide range of virtual learning facilities. They utilized various social media sites, amongst them Facebook, Instagram, Telegram, WhatsApp, and WeChat, to apply synchronous or asynchronous classroom discussion, facilitate peer explanations using either voice notes or texts, and deliver assignments and quizzes. Lecturers were obliged to provide students with access to online materials, resources, links to digital libraries, repositories such as Open Educational Resources, internet streaming, torrents, or broadcasts. Academia contacted students and delivered lessons through educational platforms such as Zoom, Google Hangouts, learning management systems (LMSs) etc. (Lapada et al., 2020; Rahiem, 2020). The circumstances caused by the pandemic have caused m-learning to become widespread, involving the utilization of mobile and portable IT devices. Significant features hereof include a focus on learning mobility and emphasis on the progressive adjustment of the mobile population by social institutions. Furthermore, the smartphone has been identified as the most popular gadget amongst young people (Lapada et al., 2020).

Such vast expansion of media, and social media in particular, into the domain of education stimulated "a social process in all educational contexts" and empowered "building effective learning communities, where collective knowledge is created and advanced while supporting the growth of individual knowledge" (Lahiri \& Moseley, 2015, p. 73). Therefore, it is essential for students to develop core media literacy skills. Amongst these skills should be the ability to pool knowledge amongst the abundance of information in the virtual environment and the ability to assess the trustworthiness and authenticity of information sources. In addition, students should possess the ability to analyze and synthesize found information and to participate in various online communities regarding and respecting diverse points of view, grasping and following alternative norms (Lantz-Andersson, 2016).

Forming the media literacy skills of EFL students by implementing social media resources into EFL courses is a stimulating and demanding task for the language teacher who seeks to master interdisciplinary knowledge aquistion whilst inspiring students to master it alongside them (Westman, 2019). Media content is 
used in the EFL classroom to connect theoretical knowledge with real-life events and policies. However, to be aware of the true sense of these phenomena, students need to be media literate. The following are the purposes of using media in an EFL setting:

1) To develop different linguistic competences. Recent surveys have proven that students' receptiveness toward the use of multiple social media tools for foreign-language learning enhances their experience of its application (Bilotserkovets \& Gubina, 2019; Mc Dermott, 2013). In addition, it provides students with the training necessary to take computer-based tests of English, such as PTE Academic, TOEFL etc., to participate in telecollaboration in the field of language learning and online academic exchange programs around the world (Kobzhev et al., 2020). Lastly, it enables successful cross-cultural communication between students (Dvorghets \& Shaturnaya, 2015).

2) To focus on the values and tendencies of the foreign-language society. Gómez Jiménez and Gutiérrez (2019) noted that the implementation of social media tools within an educational context contributes to the creation of an advantageous academic environment, turning EFL classrooms into peculiar spaces where "different linguistic and cultural worlds come into contact" (p. 94). Through this, students' linguistic and intercultural competences together with their media literacy skills are promoted.

3) To provoke the discussion of ideas reflected in the media content. In the process of incorporating media literacy tools into the EFL training process, students develop their critical thinking skills. They do this by studying the influence of subjective factors on the objectivity of media content and forming an interest in studying different sources of media information and comparing diverse opinions. It is important for every ordinary citizen, especially a young one, be able to critically comprehend media information and identify opportunities for the positive or negative impact of information disseminated by different types of media to prevent their possible manipulative impact (Van Den Beemt et al., 2020).

The outcomes of our study revealed that educators implementing media literacy tools should provoke students to participate in dialogue, teaching them not to be afraid to express their opinion, as well as to argue it, to form their critical thinking skills. This is essential because the media environment is both a field for producing meanings for the mass consciousness and a means of manipulating it (Ytreberg, 2002). Media literate students are supposed to be able to critically and consciously evaluate media messages. They need to be taught to 'read between the lines', identify the language of manipulation and persuasion, differentiating between the text and the subtext (Krakid et al., 2014). Besides, "ignoring what students do with a foreign language outside the classroom or refusing to engage with students in social media, teachers will never truly understand their needs and never fully realize the potential of social media as a language learning tool" (Tantarangsee et al., 2017, p. 476). 


\section{Conclusion}

The findings of the study revealed improvement in the experimental group's media literacy skills and English-language proficiency compared to that of the control group. Being restricted to using mostly digital and virtual facilities because of the lockdown due to the COVID-19 pandemic, students and academics were able to express themselves and communicate through social media, search for information, and consciously perceive and critically interpret information obtained from different media. In addition, they were able to separate reality from its virtual imitation (i.e. understand the reality constructed by media sources), comprehend the manipulating tools they create, successfully use media technologies to solve professional problems etc. Concurrently, the positive dynamics of EFL-proficiency improvement was observed due to the growing motivation of applying English in real communication practice, authentic English learning materials, and ICT and interactive teaching technologies constructed into the academic process with the help of social media. However, beyond this study, additional experimentation is needed to quantitate and evaluate the progress of students in written and spoken English involved in social media and internet and web content evaluation activities via the use of critical questioning on the part of the students.

\section{References}

ACTFL. (n.d.). Literacy in language learning. https://www.actfl.org/guidingprinciples/literacy-language-learning

Andriushchenko, K., Rozhko, O., \& Tepliuk, M. (2020). Digital literacy development trends in the professional environment. International Journal of Learning, Teaching and Educational Research, 19(7), 55-79. https://doi.org/10.26803/ijlter.19.7.4

Assalahi, H. (2020). Learning EFL online during a pandemic: Insights into the quality of emergency online education. International Journal of Learning, Teaching and Educational Research, 19(11), 203-222. https://doi.org/10.26803/ijlter.19.11.12

Baglari, H., Sharma, M. K., Marimuthu, P., \& Suma, N. (2020). Pattern of social media use among youth: Implication for social media literacy. Mental Health Addiction Research, 5, 1-5. https://doi.org/10.15761/MHAR.1000189

Bal, E., \& Bicen, H. (2017). The purpose of students' social media use and determining their perspectives on education. Procedia Computer Science, 120, 177-181. (9th International Conference on Theory and Application of Soft Computing, Computing with Words and Perception, ICSCCW 2017, 22-23 August 2017, Budapest, Hungary.) https:// doi.org/10.1016/j.procs.2017.11.226

Bilotserkovets, M., \& Gubina, O. (2019). Target language teaching by means of e-learning: A case study. Revista Romaneasca pentru Educatie Multidimensionala, 11(4), 17-29. https://doi.org/10.18662/rrem/154

Brocca, N. (2020). Sozial medien in bildung und fremdsprachdidaktik: Einleitung [Social media in education and foreign language teaching: An introduction]. heiEDUCATION Journal, 5, 9-23. https://doi.org/10.17885/heiup.heied.2020.5.24155

Bubich, O. A., Gilevich, E. G., Lushchinskoi, O. V., \&. Savich, E. V. (2016). Clip thinking and organization of the pedagogical process at the university. Modeling of effective speech communication in the context of academic and professionally oriented interaction. BSU, 65-71. https://elib.bsu.by/bitstream/123456789/159350/1/6571.pdf 
Chen, B., \& Bryer, T. (2012). Investigating instructional strategies for using social media in formal and informal learning. The International Review of Research in Open and Distributed Learning, 13(1), 87-104. https://doi.org/10.19173/irrodl.v13i1.1027

Dvorghets, O. S., \& Shaturnaya, Y. A. (2015). Developing students' media literacy in the English language teaching context. Procedia - Social and Behavioral Sciences, 200, 192-198.

Goh, P. S., \& Sandars, J. (2020). A vision of the use of technology in medical education after the COVID-19 pandemic. MedEdPublish, 9(1). https://doi.org/10.15694/mep.2020.000049.1

Gómez Jiménez, M. C., \& Gutiérrez, C. P. (2019). Engaging English as a foreign language students in critical literacy practices: The case of a teacher at a private university. Profile: Issues in Teachers' Professional Development, 21(1), 91-105. https://doi.org/10.15446/profile.v21n1.71378

Hatlevik, O. E., Ottestad, G., \& Throndsen, I. (2015). Predictors of digital competence in 7th grade: A multilevel analysis. Journal of Computer Assisted Learning, 31(3), 220-231. https://doi.org/10.1111/jcal.12065

He, H. (2019). Media literacy education and second language acquisition. The $\begin{array}{llll}\text { International Encyclopedia of Media Literacy, } & \text { 1-7. }\end{array}$ https://doi.org/10.1002/9781118978238.ieml0125

Karpov, A. V., \& Ponomareva, V. V. (2000). Psychology of reflexive control mechanisms (p. 283). IPRAN.

Kobzhev, A., Bilotserkovets, M., Fomenko, T., Gubina, O., Berestok, O., \& Shcherbyna, Y. (2020). Measurement and assessment of virtual internationalization outcomes in higher Agrarian education. Postmodern Openings, 11(1Supl1), 78-92. https://doi.org/10.18662/po/11.1sup1/124

Krakid, A.-M., Skledar Matijevid, A., \& Babovid, N. J. (2014, September 11-12). Seeing is (not) believing: Teaching media literacy through ELT. [Conference session]. In The International Language Conference on The Importance of Learning Professional Foreign Languages for Communication between Cultures, Maribor, Slovenia. https://bib.irb.hr/datoteka/803370.Kraki_Skledar_Matijevi_Jurina_Babovi.pdf

Kuzmina, M. V. (2011). Diagnosis of forming of media culture of students in process of creation of educational video materials. Theory and Practice of Social Development, $8,162-164$.

Lahiri, M., \& Moseley, J. L. (2015). Learning, unlearning and relearning with cutting edge technologies. International Journal of Learning, Teaching and Educational Research, 13(3), 62-78.

Lantz-Andersson, A. (2016). Embracing social media for educational linguistic activities. Nordic Journal of Digital Literacy, 11(1), 50-77. https:// doi.org/10.18261/issn.1891-943x-2016-01-03

Lapada, A. A., Miguel, F. F., Robledo, D. A. R., \& Alam, Z. F. (2020). Teachers' Covid-19 awareness, distance learning education experiences and perceptions towards institutional readiness and challenges. International Journal of Learning, Teaching and Educational Research, 19(6), 127-144. https://doi.org/10.26803/ijlter.19.6.8

Mc Dermott, G. (2013). The role of social media in foreign language teaching: A case study for French. Recherche et Pratiques Pédagogiques en Langues de Spécialité, 32(2), 141-157. https://doi.org/10.4000/apliut.4234

Marinoni G., Van Land, H., \& Jensen, T. (2020). The impact of Covid-19 on higher education around the world. IAU Global Survey Report. 
https://www.unibasq.eus/wp-content/uploads/2020/06/iau_covid19_and_he _survey_report_final_may_2020.pdf

Mendoza, K. (2018, November 19). 5 Questions students should ask about media. Common sense education. https://www.commonsense.org/education/blog/5questions-students-should-ask-about-media

Ogbonnaya, U. I., Awoniyi, F. C., \& Matabane M. E. (2020). Move to online learning during COVID-19 lockdown: Pre-service teachers' experiences in Ghana. International Journal of Learning, Teaching and Educational Research, 19(10), 286-303. https://doi.org/10.26803/ijlter.19.10.16

Pfeffer, T. (2014). Academic media literacy and the role of universities. Perspectives of Innovations, Economics and Business, 14(2), 83-93. https://doi.org/10.15208/pieb.2014.10

Rahiem, M. D. H. (2020). The emergency remote learning experience of university students in Indonesia amidst the COVID-19 crisis. International Journal of Learning, Teaching and Educational Research, 19(6), 1-26. https://doi.org/10.26803/ijlter.19.6.1

Reagan, T., \& Osborn, T. (2002). Critical curriculum development in the foreign language classroom. In T. G. Reagan \& T. A. Osborn (Eds.), The foreign language educator in society: Toward a critical pedagogy (pp. 70-81). Coursework.

Schmidt, H. (2012). Media literacy education at the university level. The Journal of Effective Teaching, 12(1), 64-77. https:// files.eric.ed.gov/fulltext/EJ1092140.pdf

Tantarangsee, C., Kosarassawadee, N., \& Sukweses, A. (2017). The use of social media in teaching and learning: A case of SSRU's faculty members. International Journal of Innovation, Management and Technology, 8(6), 471-476. https://doi.org/10.18178/ijimt.2017.8.6.773

Van Den Beemt, A., Thurlings, M. \& Willems, M. (2020). Towards an understanding of social media use in the classroom: A review. Technology, Pedagogy and Education, 29(1), 35-55. https:// doi.org/10.1080/1475939X.2019.1695657

Westman, P. (2019). Using critical media literacy to support English language teaching and practice. Revista Lusófona De Estudos Culturais, 1(1). https://doi.org/10.21814/h2d.242

Ytreberg, E. (2002). Erving Goffman as a theorist of the mass media. Critical Studies in Media Communication, 19(4), 481-497. https://doi.org/10.1080/07393180216570 


\section{Appendix 1}

\section{Questionnaire "Social media in students' life"}

Dear students, please answer the questions. The questionnaire will be anonymous. The value of the research depends on how openly and in detail you answer the questions.

Thank you in advance for your participation!

\section{Section 1: Kinds of social media}

1. What kind of social media do you usually use?

2. What purposes do you mostly use social media for?

Choose the activities mostly you do on social media.

\begin{tabular}{|l|l|}
\hline \multicolumn{1}{|c|}{ Activities } & \multicolumn{1}{|c|}{$\begin{array}{c}\text { The activities you do } \\
\text { most often }(\sqrt{ })\end{array}$} \\
\hline communication with classmates, friends, relatives & \\
\hline making new acquaintances & \\
\hline searching for interesting information & \\
\hline posting some ads & \\
\hline reading blogs & \\
\hline reading the news & \\
\hline searching interest groups & \\
\hline $\begin{array}{l}\text { using multimedia (viewing photos, movies, listening to } \\
\text { music) }\end{array}$ & \\
\hline uploading photos & \\
\hline learning languages & \\
\hline communication with foreigners & \\
\hline
\end{tabular}

Section 2: Social media use for educational purposes

1. What kinds of social media do you use for educational purposes?

2. How frequently do you use social media for study?

3. What kinds of social media do you use in learning English?

4. How often do you use social media in learning English?

\section{Appendix 2}

Questionnaire "Self-assessment of media competence skills"

Dear students, please evaluate your ability and readiness (on a five-point scale, where: 1 - no, 2 - rather "no" than "yes", 3 - rather "yes" than "no", 4 - yes, 5 rather obvious) to work with social media:

\begin{tabular}{|l|l|l|l|l|l|}
\hline Skills & $\mathbf{1}$ & $\mathbf{2}$ & $\mathbf{3}$ & $\mathbf{4}$ & $\mathbf{5}$ \\
\hline $\begin{array}{l}\text { to benefit from the virtual participation in a team } \\
\text { work }\end{array}$ & & & & \\
\hline $\begin{array}{l}\text { to interact with other team members in the } \\
\text { virtual social environment }\end{array}$ & & & & & \\
\hline $\begin{array}{l}\text { to explore and acquire new roles, such as } \\
\text { mentors, mediators and group leaders in a } \\
\text { virtual group }\end{array}$ & & & & \\
\hline $\begin{array}{l}\text { to exchange practical and academic information, } \\
\text { experiences, social support with other } \\
\text { participants }\end{array}$ & & & & & \\
\hline
\end{tabular}




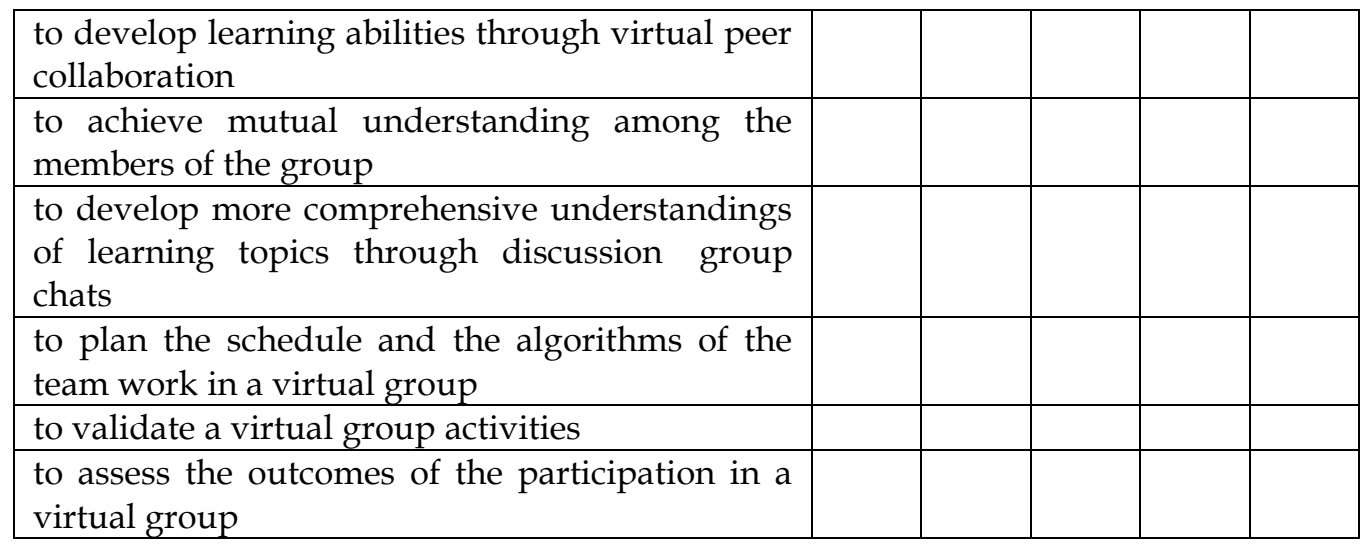

\section{Appendix 3}

Questionnaire "Social media activities in learning English"

\section{Section 1: What social media activities do you usually use for learning English?}

Dear students! Please, point out the priority of social media activities that had contributed to your English language improvement.

\begin{tabular}{|l|c|}
\hline \multicolumn{1}{|c|}{ Social media activities for learning English } & $\begin{array}{c}\text { The prior social media } \\
\text { activities }(\sqrt{ })\end{array}$ \\
\hline searching for information & \\
\hline use of authentic learning materials & \\
\hline reading news & \\
\hline communication with foreigners & \\
\hline social media projects & \\
\hline $\begin{array}{l}\text { participation in the Moodle and other social media } \\
\text { forums }\end{array}$ & \\
\hline
\end{tabular}

Section 2: How did the implementation of social media help you in learning English?

Dear students! Read the suggested statements carefully. Assess their significance to you.

\begin{tabular}{|l|l|}
\hline \multicolumn{1}{|c|}{$\begin{array}{c}\text { The factors that influence the students' } \\
\text { English proficiency improvement }\end{array}$} & $(\sqrt{ })$ \\
\hline Increasing motivation & \\
\hline Communication skills practice & \\
\hline $\begin{array}{l}\text { Authentic learning materials from social } \\
\text { media }\end{array}$ & \\
\hline ICT application in the process of learning & \\
\hline Interactive teaching techniques & \\
\hline
\end{tabular}

